\title{
Further characterization and pathogenicity of Didymella microchlamydospora causing stem necrosis of Morus nigra in Iran
}

\author{
S. Akram Ahmadpour, Reza Farokhinejad and Mehdi Mehrabi-Koushki
}

Plant Protection Department, Agriculture Faculty, Shahid Chamran University of Ahvaz, Khuzestan Province, Iran

Ahmadpour SA, Farokhinejad R, Mehrabi-Koushki M 2017 - Further characterization and pathogenicity of Didymella microchlamydospora causing stem necrosis of Morus nigra in Iran. Mycosphere 8(7), 835-852, Doi 10.5943/mycosphere/8/7/3.

\begin{abstract}
In the last decade, canker and dieback diseases have caused disease of ornamental and fruit trees of Khuzestan Province in the southwest of Iran. Fourty-eight symptomatic branches and trunks were sampled and a survey was made to identify the probable pathogens, which led to the isolation of the recently established species, Didymella microchlamydospora. A multi-locus DNA sequence based phylogeny, in combination with morphology, was used to characterize seven isolates of this species. Two phylogenetic trees constructed based on the combined sequences of ITS/LSU/tub2 and ITS/LSU/tub2/rpb2 regions showed very little differences, and both trees presented generally consistent relationships among the strongly supported clades. In both of threeand four-locus based phylogenetic trees, our isolates and a reference strain, D. microchlamydospora CBS 105.95, formed supportive monophyletic clades with strong 99\% and 100\% BS support, respectively. In pathogenicity tests, the isolate of D. microchlamydospora SCUA 14_Dez_Mor formed the necrosis and wood discoloration on stem fragments of Morus nigra. To our knowledge, this is the first report of pathogenicity of D. microchlamydospora on Morus nigra and its association on plants of olive, bitter orange, oleander and bottlebrush worldwide. In addition, we gave a slightly amended description of this species.
\end{abstract}

Key words - die back - Khuzestan - multi-locus phylogeny

\section{Introduction}

Canker and dieback diseases are common, widespread, and destructive on a wide range of woody plants (Shurtleff 1997, Horst 2013). These diseases are caused by several fungal taxa belonging to the different families including Botryosphaeriaceae and Didymellaceae (Phillips et al. 2013, Chen et al. 2015) in Dothideomycetes and Cytospora and Diaporthe in Sordariomycetes (Sinclair et al. 1987, Lawrence et al. 2015). In the last decade, these diseases have threatened the ornamental and fruit trees of Khuzestan Province in the southwest of Iran. The potential pathogens infect all woody plants, especially those low in vigor. The disease causes stem necrosis and canker, wilting and dieback of twigs and branches (unpublished data).

The species D. microchlamydospora (Aveskamp \& Verkley) Q. Chen \& L. Cai (formerly known Phoma microchlamydospora) belongs to the recently established family Didymellaceae (de Gruyter et al. 2009, Hyde et al. 2013), which includes many taxa previously classified in the genus Phoma and their related taxa (Chen et al. 2015). This species has been isolated from leaves of Eucalyptus sp. and an unknown plant (Aveskamp et al. 2009). The genus Didymella sensu lato was 
established by Saccardo (1880) to accommodate D. exigua (Niessl) Sacc. (Holm 1975, Corlett 1981). This genus was originally placed in Mycosphaerellaceae, and then subsequently reclassified in the Pleosporaceae, Phaeosphaeriaceae and Venturiaceae (Hyde et al. 2013, Wijayawardene et al. 2014, Chen et al. 2015). In recent years, phylogenetic studies have resulted in the dramatic taxonomic changes in Didymella and other Phoma-like taxa (Aveskamp et al. 2009, 2010, de Gruyter et al. 2009, Woudenberg et al. 2009, Chen et al. 2015). In order to resolve phylogenetic relationships and improve the systematics of Phoma and allied genera, ITS, LSU, tub2 and rpb2 sequences were used for species demarcation (Aveskamp et al. 2009, 2010, Woudenberg et al. 2009, Chen et al. 2015). According to the most recent phylogenetic analysis of Phoma-like taxa (Chen et al. 2015, Hyde et al. 2016), Didymella sensu stricto (Didymella Sacc. ex Sacc., Syll. Fung. 1: 545. 1882. emend. Q. Chen \& L. Cai.) was accommodated in the recently introduced family of Didymellaceae (de Gruyter et al. 2009). The molecular phylogenetic studies showed that the family Didymellaceae includes most members of Phoma and related asexual genera including the new emended and introduced genera of Phoma, Ascochyta, Didymella, Epicoccum, Stagonosporopsis, Allophoma, Heterophoma, Boeremia, Paraboeremia, Macroventuria, Phomatodes, Calophoma, Leptosphaerulina, Neoascochyta, Xenodidymella, Nothophoma, Neodidymelliopsis, Neodidymella and Neomicrosphaeropsis. Didymella had first been identified as paraphyletic taxon within the Didymellaceae (Aveskamp et al. 2010), then a comprehensive phylogenetic analysis of Didymellaceae was carried out (Chen et al. 2015), and in which Didymella was emended as monophyletic genus to accommodate 35 known and two unknown species. In the Chen et al. (2015) study, the genus Didymella was emended to accommodate the species of Didymella exigua, D. microchlamydospora, D. acetosellae, D. aliena, D. americana, D. anserina, D. arachidicola, D. aurea, D. bellidis, D. boeremae, D. calidophila, D. chenopodii, D. coffeae-arabicae, D. dactylidis, D. dimorpha, D. eucalyptica, D. gardeniae, D. heteroderae, D. lethalis, D. longicolla, D. macrostoma, D. maydis, D. molleriana, D. musae, D. negriana, D. pedeiae, D. pinodes, D. pomorum, D. rhei, D. viburnicola, D. rumicicola, D. sancta, D. senecionicola, D. subglomerata, D. subherbarum, D. curtisii, D. glomerata, D. nigricans, D. pinodella, D. protuberans and two unidentified species. Recently, Didymella cirsii was added (Liu et al. 2015).

The genus Didymella is widely distributed in field and ornamental crops as well as in wild plants (Chen et al. 2015). The species of this genus are mainly saprobes that are commonly found in living or dead aerial parts of herbaceous and wooden plants (Chen et al. 2015); some of them also act as mutualistic endophytes with some plant species (Rayner 1922). Very little is known about the pathogenicity of Didymella sensu stricto. However, a small number of species belonging to newly recombined genus of Didymella was reported as plant pathogen (Tivoli and Banniza 2007, Barilli et al. 2016). The species Didymella pinodes (formerly known Mycosphaerella pinodes) was reported as main causal agent of Ascochyta blight, one of the most important fungal diseases of pea worldwide (Tivoli and Banniza 2007, Barilli et al. 2016). In addition, Didymella tanaceti (Syn: Microsphaeropsis tanaceti haplotype I) and D. rosea (Syn: M. tanaceti haplotype II) were reported as plant pathogens, that caused tan spot of pyrethrum (Pearce et al. 2016).

According to the current literature (Aveskamp et al. 2009, Chen et al. 2015), two known strains of Didymella microchlamydospora (CBS 105.95 and CBS 491.90) were regarded as saprobes (Chen et al. 2015). In this study change it is evident that this species can cause dieback and necrosis. Here, seven isolates of Didymella microchlamydospora were identified using phylogenetic analysis based on ITS, LSU, tub2 and rpb2 sequence data. The morphology and pathogenicity of these isolates is also characterized.

\section{Materials \& Methods}

\section{Collection of specimens}

The specimens were collected from the township of Andimeshk, Ahvaz and Dezful Khuzestan Province in the southwest of Iran. This climate is hot semi-arid (Koppen climate classification BSh) with extremely hot summers and mild winters. These areas are generally very 
hot and occasionally humid, while summertime temperatures routinely exceed $45 \mathrm{C}$ and in the winter, it can rarely drop below freezing. Rainfall is almost exclusively confined to the period from November to April. During 2015-2016, 48 symptomatic branches and trunks were sampled from the trees of olive (Olea spp), bitter orange (Citrus aurantium), blackberry (Morus nigra), oleander (Nerium oleander) and Bottlebrush (Callistemon viminalis), with the symptoms of dieback, yellowing and defoliation (Fig. 1). The samples were packed in paper bags and transferred to the lab.
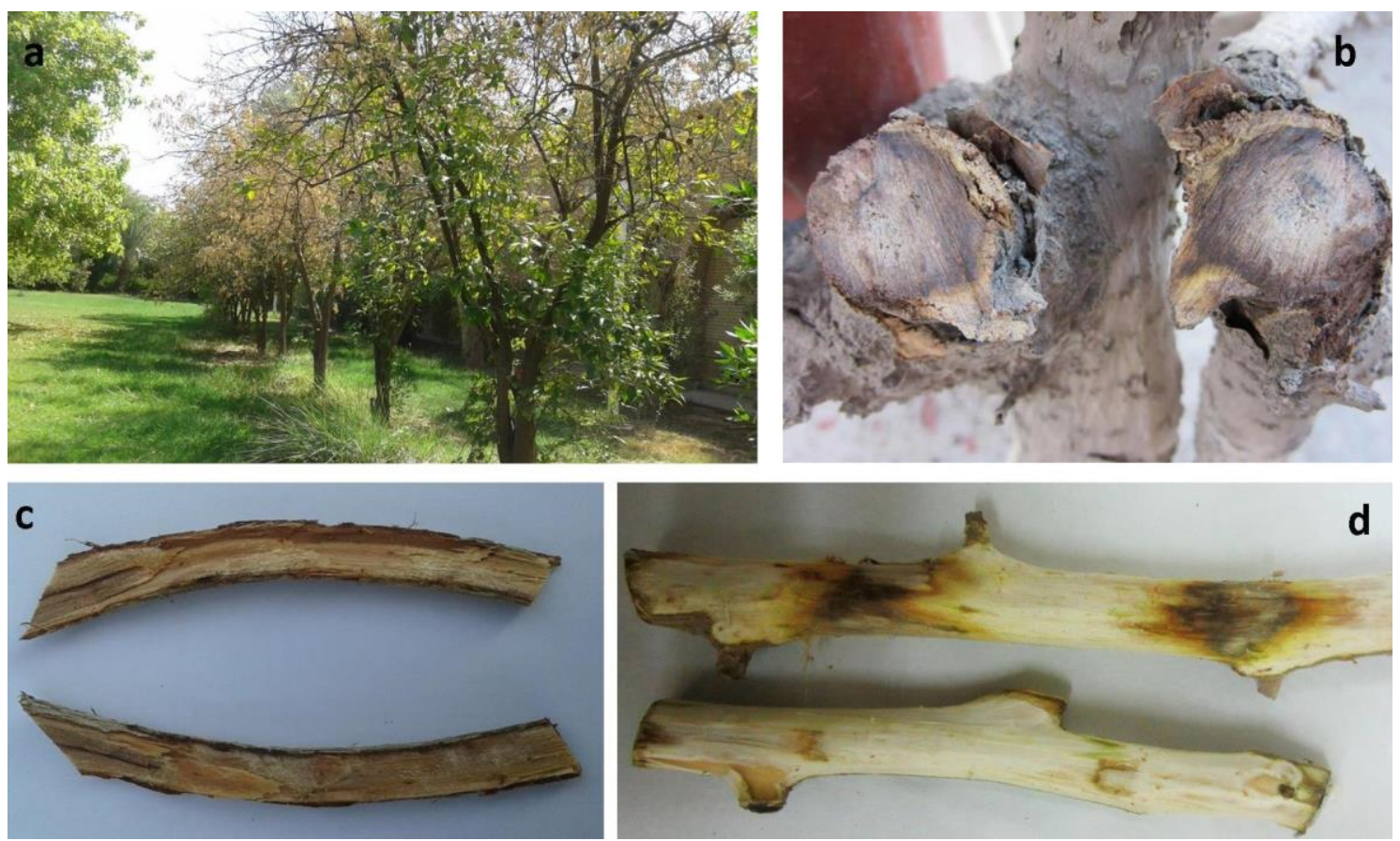

Figure 1 - a The symptoms of die back and decline on Citrus aurantium. b The symptoms of stem canker and wood discoloration on Morus nigra. c Necrosis and discoloration of branches in Callistemon viminalis. $\mathrm{d}$ Pathogenecity test, necrosis symptom on a stem fragment of Morus nigra caused by pathogenic isolate of D. microchlamydospora SCUA 14_Dez_Mor (top) compared to a control fragment (bottom).

\section{Isolation and purification}

The small pieces $(0.3-1 \mathrm{~cm})$ from healthy and discolored margins of symptomatic branches and dead stems were excised and surface-sterilized by dipping them in $2 \%$ sodium hypochlorite (24 minutes), followed by washing three times with sterile distilled water $(2 \mathrm{~min})$. Then, the fragments were plated on petri plates containing potato dextrose agar (PDA, Difco, USA) supplemented with streptomycin $(30 \mathrm{mg} / \mathrm{L})$. The plates were incubated up to 5-15 days at $28 \mathrm{C}$, and individual colonies were cultured to PDA. The isolates were purified by single spore method. The spore suspension was prepared and $100 \mu \mathrm{L}$ of which plated on a $1 / 4$-strenght PDA. The plates incubated in the dark at $28 \mathrm{C}$ for 24-48 hours and individual small colonies sub-cultured on PDA as single-spore isolates. The living cultures of the isolates were deposited in the Collection of Fungal Cultures, Department of Plant Protection, Shahid Chamran University of Ahvaz, Iran (SCUA 11SCUA 17).

\section{Microscopy and growth indicators}

The isolates of Didymella were grown on potato dextrose agar (PDA, Merck) and corn meal agar (CMA, Sigma Aldrich) at $28 \mathrm{C}$, with 12 hours fluorescent light and 12 hours darkness. The diameter of colonies was daily measured up to 10-day incubation. Morphological characters were made at 3-25 days post-inoculation and the colour rate was determined according to the Methuen handbook of color (Kornerup \& Wanscher 1967). The microscopic preparations were made by 
using the method of Riddle (1950) and Measurements were carried out with the $40 \times$ and $100 \times$ objective lens of a Leitz wetzlar (SM-LUX) Basic Biological Light Microscope. The sizes of characteristic structures were recorded with 50-70 measurements for each structure. The photomicrographs were made with an OLYMPUS BX51 microscope fitted with an OLYMPUS DP12 digital camera. Macroscopic and microscopic morphological characters were used to compare the isolated fungal taxa with the assistance of current mycological literature (Aveskamp et al. 2009, Chen et al. 2015). Then, for accurate identification, the isolates were subjected to DNA analysis.

\section{Pathogenicity test}

The stem fragments of each trees with similar height, diameter, and vigor were selected. After surface sterilizing the fragments with $2 \%$ sodium hypochlorite (2-4 min) and washing by sterilized distilled water, a 3-mm-diameter hole was made to the depth of the cambium at 2-3 cm from both sides of each stem using a scalper. A small quantity of inoculum taken from active-growing edge of the colonies Didymella microchlamydospora isolates was inoculated into each wound. Free culture media was placed into wounds as control. The replicates of each treatment were separately placed into water containing desiccators, sterilized as moist chamber. The desiccators were incubated at $28^{\circ} \mathrm{C}$ for 3 to 6 weeks after inoculation. Pathogenicity of each isolate were evaluated 3 to 6 weeks after inoculation by indicating: (i) the presence or absence of callus around the wound, (ii) the growth and sporulation of fungus in bark surrounding the inoculation point, (iii) the extent of external longitudinal spread of lesions and (iv) the internal longitudinal spread of discoloration in xylem.

\section{DNA extraction and amplification}

The mycelial biomass of Didymella isolates grown into flasks containing potato dextrose broth (PDB) was harvested by passing through sterilized filter papers. The mycelia were freezedried (Freeze-Dryer, Alpha 1-2LD Plus, Christ) and powdered in the mortar containing liquid nitrogen. The genomic DNA was isolated according to modified method established by Reader and Broda (1985). The mycelial powder was lysed with a lysis buffer and then extracted three times by Phenol:chloroform:isoamyl alcohol. The genomic DNA was recovered through ethanolprecipitation typical method. The DNAs were qualified and quantified using Spectrophotometer (Eppendorf BioPhotometer plus) and loading on the gel. The partial regions of ITS-LSU, rpb2 and tub2 were amplified using the primer pairs of ITS1/ NL4 (White et al. 1990, O'Donnell 1993), RPB2-5F2/ fRPB2-7cR (Liu et al. 1999, Sung et al. 2007) and Btub2Fd/ Btub4Rd (Woudenberg et al. 2009), respectively. PCR reactions were completed in $50 \mu \mathrm{L}$ final volumes and consisted of 5 $\mu \mathrm{L} 10 \times$ prime Taq Reaction Buffer (GenBio, South Korea), $6 \mu \mathrm{L} \mathrm{MgCl}_{2}(25 \mathrm{mM}), 0.6 \mu \mathrm{L}$ Prime Taq DNA Polymerase (5U/ $\mu), 2 \mu \mathrm{L}$ of each primer (10mM), $2 \mu \mathrm{L}$ dNTP (10mM mix), 100-500ng DNA and miliqure water up to $50 \mu \mathrm{L}$. The amplification were performed in a thermocycler (MJ Mini $^{\mathrm{TM}}$ Gradient Thermal Cycler) and run with a temperature profile described in the following: the PCR cycling were for ITS-LSU amplification, initial melting at $94 \mathrm{C}$ for 5 minutes, 35 cycles each of 30 seconds at $94 \mathrm{C}, 30$ seconds at $57 \mathrm{C}$, and 90 seconds at $72 \mathrm{C}$ and followed with a final extension at $72 \mathrm{C}$ for 10 minutes, for the tub2 amplification, initial melting at $94 \mathrm{C}$ for 5 minutes, 35 cycles each of 30 seconds at $94 \mathrm{C}, 30$ seconds at $58 \mathrm{C}$, and 60 seconds at $72 \mathrm{C}$ and followed with a final extension at $72 \mathrm{C}$ for 10 minutes and for the rpb2 amplification, initial melting at $94 \mathrm{C}$ for 5 minutes, 35 cycles each of 30 seconds at $94 \mathrm{C}, 30$ seconds at $57 \mathrm{C}$, and 60 seconds at $72 \mathrm{C}$ and followed with a final extension at $72 \mathrm{C}$ for 10 minutes.

\section{Sequencing and phylogenetic analyses}

PCR products were purified through ethanol-precipitation method (Crouse \& Amorese 1987) and then sequenced using forward and reverse primers by Macrogen Company. The Sequences obtained from each primer pairs were assembled using DNA Baser Sequence Assembeler v4 programs (2013, Heracle BioSoft, www.DnaBaser.com). The phylogenetic analysis of Didymella 
microchlamydospora isolates was carried out with including the reference sequences belonging to the known genera of Didymellaceae and species of Didymella (225 available sequences mostly from Aveskamp et al. 2010 and Chen et al. 2015 included) (Table 1). The species of Pleospora betae were used as outgroup taxon to root phylogenetic trees.

The sequences of ITS, LSU, tub2 and $\mathrm{rpb} 2$ were aligned individually using ClustalW in BioEdit v. 7.0.9.0 (Hall 1999), trimmed to the same starting position and then assembled. The combined ITS-LSU-tub2 and ITS-LSU-tub2-rpb2 datasets were multiple-aligned using ClustalW in BioEdit v. 7.0.9.0 (Hall 1999). Phylogenetic analysis was performed with maximum parsimony and maximum likelihood algorithm. Phylogenetic trees were constructed using MEGA version 6 (Tamura et al. 2013). Best-fitting ML nucleotide substitution model for each dataset was determined using the model test function in MEGA version 6. The phylogenetic trees were constructed with Subtree-Pruning-Regrafting (SPR) algorithm and following options: Gaps (insertion/deletions) were treated as missing data, Bootstrap (BP) analyses were done with 1000 replicates, Initial Trees for ML were made by NJ/BioNJ algorithm and Branch Swap Filter was set very strong. Two final alignments used for phylogenetic analyses were deposited in TreeBASE (http://purl.org/phylo/treebase/phylows/study/TB2:S21100).

\section{Results}

\section{Morphological characterization (Fig. 2)}

Hyphae diameter in 14-day colonies $2.5-4 \mu \mathrm{m}(\overline{\mathrm{x}}=3.2 \mu \mathrm{m}, \mathrm{n}=50)$. Conidiomata pycnidial, pycnidia mostly solitary or aggregated, superficial on or submerged into the agar, dark brown, with age becoming darker, variable in shape and size (macro-and micro-pycnidium). Macropycnidia globose, glabrous or covered with hyphal outgrows, 100-190 × 100-190 $\mu \mathrm{m}(\overline{\mathrm{x}}=139 \times 139 \mu \mathrm{m}, \mathrm{n}$ $=50$ ) (Fig. 2). Ostioles 1-3, papillate, rarely on a distinct neck. Pycnidial wall pseudoparenchymatous, composed of oblong to isodiametric cells, 2-5 layers. Micropycnidia globose to subglobose, glabrous or covered with hyphal outgrows, 50-80 $\times(40-) 49-70(-80) \mu \mathrm{m}(\overline{\mathrm{x}}$ $=61 \times 59 \mu \mathrm{m}, \mathrm{n}=50)$. Conidia hyaline to pale brown, smooth- and thin-walled, subglobose to ellipsoidal, aseptate and guttulate, (2.5)3-5.5(6) $\times(1.5) 2-3.2(3.8) \mu \mathrm{m}(\overline{\mathrm{x}}=4.3 \times 2.4 \mu \mathrm{m}, \mathrm{n}=70)$. Chlamydospores mostly unicellular, solitary or in chain, intercalary or terminal, smooth, brown, globose to subglobose, (3)4-7.5(10) $\times(2.5) 3-7.5 \mu \mathrm{m}(\overline{\mathrm{x}}=5.9 \times 4.6 \mu \mathrm{m}, \mathrm{n}=50)$. Multicellular Chlamydospores (pseudosclerotioid and dictyosporous) variable in shape and size, brown, intercalary, sparse and solitary, smooth.

Colonies on PDA, 70-80 mm diameter after 10 days of incubation at $28 \pm 0.5 \mathrm{C}$, blackishbrown with whitish cream margins at early growth stage, with age becoming blackish green in the central and olivaceous green in the edge, staining the agar in pink collar due to the production of a diffusible pigment, floccose growth, the rings of sporulation containing black pycnidia becoming darker and compacter towards the center of the colony; reverse blackish green with creamy to orange edges, leaden black in zones with abundant pycnidia, darkening towards the center of the colony. Colonies on CMA, 65-75 mm diameter after 10 days of incubation at $28 \pm 0.5 \mathrm{C}$, grey to brownish grey with lighter edge, smooth, the pycnidia appear as scattered small dots of brown to black or rings of sporulation; reverse grey to olivaceous green with lighter edge, leaden blackish brown in pycnidia containing zone.

Material examined - IRAN, Khuzestan Province, Andimeshk, on dead branch of Olea europaea, 11 August 2015, S.A. Ahmadpour (SCUA 11_And_Ole); Ahvaz, on dead branch of Olea europaea, 12 Oceober 2015, S.A. Ahmadpour (SCUA 12_Ahw_Ole); on dead branch of Citrus aurantium, 12 Oceober 2015, S.A. Ahmadpour (SCUA 13_Ahw_Cit); on dead branch of Olea sp, 12 Oceober 2015, S.A. Ahmadpour (SCUA 16_Ahv_Ole); on dead branch of Callistemon viminalis, 12 Oceober 2015, S.A. Ahmadpour (SCUA 15_Ahv_Cal); on dead branch of Nerium sp, 12 Oceober 2015, S.A. Ahmadpour (SCUA 12_Ahv_Ner); Dezful, on dead branch of Morus nigra, 15 August 2015, S.A. Ahmadpour (SCUA 14_Dez_Mor). 
Table 1 Strains used in this study and their GenBank accession numbers. Newly generated sequences are indicated in bold.

\begin{tabular}{|c|c|c|c|c|c|c|c|}
\hline \multirow{2}{*}{ Species name } & \multirow{2}{*}{$\begin{array}{l}\text { Isolate name or } \\
\text { strain no. }\end{array}$} & \multirow{2}{*}{ Source } & \multirow{2}{*}{ Origin } & \multicolumn{4}{|c|}{ GenBank Accession number } \\
\hline & & & & ITS & LSU & rpb2 & tub2 \\
\hline $\begin{array}{l}\text { Didymella } \\
\text { microchlamydospora }\end{array}$ & $\begin{array}{l}\text { IRAN 2788C; } \\
\text { SCUA 11_And_Ole }\end{array}$ & Olea europaea & Iran & KX139019 & KX139028 & KY464923 & KY449026 \\
\hline D. microchlamydospora & $\begin{array}{l}\text { IRAN 2789C; } \\
\text { SCUA 12_Ahw_Ole }\end{array}$ & Olea europaea & Iran & KX139018 & KX139027 & KX821250 & KX821247 \\
\hline D. microchlamydospora & $\begin{array}{l}\text { IRAN 2790C; } \\
\text { SCUA 13_Ahw_Cit }\end{array}$ & Citrus aurantium & Iran & KX139014 & KX139023 & KX821249 & KX821246 \\
\hline D. microchlamydospora & SCUA 14_Dez_Mor & Morus nigra & Iran & KX139012 & KX139021 & KX821248 & KX821245 \\
\hline D. microchlamydospora & $\begin{array}{l}\text { IRAN 2791C; } \\
\text { SCUA 16_Ahv_Ole }\end{array}$ & Olea & Iran & KY449004 & KY449013 & - & - \\
\hline D. microchlamydospora & SCUA 15_Ahv_Cal & Callistemon viminalis & Iran & KY449005 & KY449014 & - & - \\
\hline D. microchlamydospora & $\begin{array}{l}\text { IRAN 2792C; } \\
\text { SCUA } 12 \text { Ahv Ner }\end{array}$ & Nerium sp. & Iran & KY449006 & KY449015 & - & - \\
\hline D. exigua & CBS 183.55 & Rumex arifolius & France & GU237794 & EU754155 & EU874850 & GU237525 \\
\hline D. acetosellae & CBS 179.97 & Rumex hydrolapathum & The Netherlands & GU237793 & GU238034 & KP330415 & GU237575 \\
\hline D. aliena & CBS 379.93 & Berberis sp. & The Netherlands & GU237851 & GU238037 & KP330416 & GU237578 \\
\hline D. americana & CBS 185.85 & Zea mays & USA & FJ426972 & GU237990 & KT389594 & FJ427088 \\
\hline D. anserina & CBS 253.80 & - & Germany & KT389498 & KT389715 & KT389595 & KT389795 \\
\hline D. arachidicola & CBS 333.75 & Arachis hypogaea & South Africa & GU237833 & GU237996 & KT389598 & GU237554 \\
\hline D. aurea & CBS 269.93 & Medicago polymorpha & New Zealand & GU237818 & GU237999 & КT389599 & GU237557 \\
\hline D. bellidis & CBS 714.85 & Bellis perennis & The Netherlands & GU237904 & GU238046 & KP330417 & GU237586 \\
\hline D. boeremae & CBS 109942 & Medicago littoralis & Australia & FJ426982 & GU238048 & KT389600 & FJ427097 \\
\hline D. chenopodii & CBS 128.93 & Chenopodium quinoa & Peru & FJ427060 & GU238053 & - & GU237591 \\
\hline D. coffeae-arabicae & CBS 123380 & Coffea arabica & Ethiopia & FJ426993 & GU238005 & КT389603 & FJ427104 \\
\hline D. curtisii & PD 92/1460 & Sprekelia sp. & The Netherlands & FJ427041 & GU238012 & KT389604 & FJ427151 \\
\hline D. eucalyptica & CBS 377.91 & Eucalyptus sp. & Australia & GU237846 & GU238007 & KT389605 & GU237562 \\
\hline D. exigua & CBS 183.55 & Rumex arifolius & France & GU237794 & EU754155 & EU874850 & GU237525 \\
\hline D. microchlamydospora & CBS 105.95 & Eucalyptus sp. & UK & FJ427028 & GU238104 & KP330424 & FJ427138 \\
\hline D. rhei & CBS 109177 & Rheum rhaponticum & New Zealand & GU237743 & GU238139 & KP330428 & GU237653 \\
\hline D. rumicicola & CBS 683.79 & Rumex obtusifolius & New Zealand & KT389503 & KT389721 & KT389622 & KT389800 \\
\hline D. sancta & CBS 281.83 & Ailanthus altissima & South Africa & FJ427063 & GU238030 & KT389623 & FJ427170 \\
\hline
\end{tabular}


Table 1 (continued)

\begin{tabular}{|c|c|c|c|c|c|c|c|}
\hline \multirow{2}{*}{ Species name } & \multirow{2}{*}{$\begin{array}{l}\text { Isolate name } \\
\text { or strain no. }\end{array}$} & \multirow{2}{*}{ Source } & \multirow{2}{*}{ Origin } & \multicolumn{4}{|c|}{ GenBank Accession number } \\
\hline & & & & ITS & LSU & rpb2 & tub2 \\
\hline Didymella sp. 1 & CBS 379.96 & Pteris sp. & The Netherlands & KT389504 & KT389722 & KT389624 & KT389801 \\
\hline Didymella sp. 2 & CBS 115.58 & Chrysanthemum roseum & Germany & KT389505 & KT389723 & KT389625 & KT389802 \\
\hline D. subglomerata & CBS 110.92 & Triticum sp. & USA & FJ427080 & GU238032 & KT389626 & FJ427186 \\
\hline D. viburnicola & CBS 523.73 & Viburnum cassioides & The Netherlands & GU237879 & GU238155 & KP330430 & GU237667 \\
\hline D. negriana & CBS 358.71 & Vitis vinifera & Germany & GU237838 & GU238116 & KT389610 & GU237635 \\
\hline D. nigricans & PD 77/919 & Actinidea chinensis & New Zealand & GU237915 & GU238001 & KT389611 & GU237559 \\
\hline D. pedeiae & CBS 124517 & Schefflera elegantissima & The Netherlands & GU237770 & GU238127 & KT389612 & GU237642 \\
\hline D. pinodella & CBS 531.66 & Trifolium pretense & USA & FJ427052 & GU238017 & KT389613 & FJ427162 \\
\hline D. pinodes & CBS 525.77 & Pisum sativum & Belgium & GU237883 & GU238023 & KT389614 & GU237572 \\
\hline D. protuberans & CBS 377.93 & Daucus carota & The Netherlands & GU237847 & GU238014 & KT389619 & GU237565 \\
\hline D. molleriana & CBS 229.79 & Digitalis purpurea & New Zealand & GU237802 & GU238067 & KP330418 & GU237605 \\
\hline D. exigua & CBS 183.55 & Rumex arifolius & France & GU237794 & EU754155 & EU874850 & GU237525 \\
\hline D. lethalis & CBS 103.25 & - & - & GU237729 & GU238010 & KT389607 & GU237564 \\
\hline D. mascrostoma & CBS 482.95 & Larix decidua & Germany & GU237869 & GU238099 & KT389609 & GU237626 \\
\hline D. maydis & CBS 588.69 & Zea mays & USA & FJ427086 & EU754192 & GU371782 & FJ427190 \\
\hline D. calidophila & CBS 448.83 & Soil & Egypt & FJ427059 & GU238052 & - & FJ427097 \\
\hline D. dactylidis & CBS 124513 & Dactylis glomerata & USA & GU237766 & GU238061 & - & GU237599 \\
\hline D. dimorpha & CBS 346.82 & Opuntiae sp & Spain & GU237835 & GU238068 & - & GU237606 \\
\hline D. gardeniae & CBS 626.68 & Gardenia jasminoides & India & FJ427003 & GQ387595 & KT389606 & FJ427114 \\
\hline D. glomerata & CBS 528.66 & Chrysanthemum sp. & The Netherlands & FJ427013 & EU754184 & FJ427013 & FJ427124 \\
\hline D. heteroderae & CBS 109.92 & Undefined material & The Netherlands & FJ426983 & GU238002 & KT389601 & FJ427098 \\
\hline Neodidymelliopsis cannabis & CBS 234.37 & Cnnabis sativa & - & GU237804 & GU237961 & KP330403 & GU237523 \\
\hline Xenodidymella applanata & CBS 205.63 & Rubus idaeus & The Netherlands & GU237798 & GU237998 & KP330402 & GU237556 \\
\hline Paraboeremia adianticola & CBS 187.83 & Polystichum adiantiforme & USA & GU237796 & GU238035 & KP330401 & GU237576 \\
\hline Ascochyta pisi & CBS 122751 & Pisum sativum & Canada & KP330432 & KP330444 & EU874867 & KP330388 \\
\hline Phomatodes aubrietiae & CBS 627.97 & Aubrietia sp. & The Netherlands & GU237895 & GU238045 & KT389665 & GU237585 \\
\hline Calophoma clematidina & CBS 102.66 & Clematis sp. & UK & FJ426988 & FJ515630 & KT389587 & FJ427099 \\
\hline Phoma herbarum & CBS 377.92 & Human leg & The Netherlands & KT389536 & KT389756 & KT389663 & KT389837 \\
\hline Macroventuria anomochaeta & CBS 525.71 & Decayed canvas & South Africa & GU237881 & GU237984 & GU456346 & GU237544 \\
\hline Leptosphaerulina australis & CBS 317.83 & Eugenia aromatica & Indonesia & GU237829 & EU754166 & GU371790 & GU237540 \\
\hline
\end{tabular}


Table 1 (continued)

\begin{tabular}{|c|c|c|c|c|c|c|c|}
\hline \multirow{2}{*}{ Species name } & \multirow{2}{*}{$\begin{array}{l}\text { Isolate name or } \\
\text { strain no. }\end{array}$} & \multirow[b]{2}{*}{ Source } & \multirow[b]{2}{*}{ Origin } & \multicolumn{4}{|c|}{ GenBank Accession number } \\
\hline & & & & ITS & LSU & rpb2 & tub2 \\
\hline Epic & CBS 125.82 & toenail & The Netherlands & FJ426995 & GU237974 & KT389631 & FJ427106 \\
\hline Stagonosporopsis hortensis & CBS 104.42 & - & The Netherlands & GU237730 & GU238198 & KT389680 & GU237703 \\
\hline Allophoma tropica & CBS 436.75 & Saintpaulia ionantha & Germany & GU237864 & GU238149 & KT389556 & GU237663 \\
\hline Heterophoma adonidis & CBS 114309 & Adonis vernalis & Sweden & KT389506 & KT389724 & KT389637 & KT389803 \\
\hline Neoascochyta exitialis & CBS 118.40 & - & - & KT389514 & KT389732 & KT389647 & KT389812 \\
\hline Pleospora betae & CBS 523.66 & Beta vulgaris & The Netherlands & FJ426981 & EU754179 & KT389670 & KT389842 \\
\hline
\end{tabular}

1 Abbreviation of culture collections: CBS: Centraalbureau voor Schimmelcultures, Utrecht, The Netherlands; PD: Plant Protection Service, Wageningen, the Netherlands; IRAN: Iranian Fungal Culture Collection, Iranian Research Institute of Plant Protection, Iran; SCUA: the Collection of Fungal Cultures, Department of Plant Protection, Shahid Chamran University of Ahvaz, Iran.

\section{DNA analysis and phylogenetic characterization}

The sequences of ITS, LSU, tub2 and rpb2 belonging to the isolates under study were submitted to GenBank (table 1) under the generic name Didymella microchlamydospora. These isolates shared $98.8 \%$ sequence identity in the ITS region (430 bp) attributed to 2 SNPs and three bp insertion/deletion, $100 \%$ sequence identity in the LSU region (590 bp), 99.7\% sequence identity in the tub2 region (306 bp) attributed to one SNPs, and $99 \%$ sequence identity in the rpb2 region $(782 \mathrm{bp})$ attributed to eight SNPs. Using a BLASTn search, the ITS sequences of seven $D$. microchlamydospora isolates showed 99-100\% sequence identity to reference strain D. microchlamydospora CBS 105.95.

Sixty-two and 55 taxa, including all described species of Didymella and a type species from all the known genera of Didymellaceae, were included in the three-locus and four-locus based phylogeny, respectively (Table 1). The composite sequence alignment was 1206 and 1809 characters in length, including alignment gaps (ITS: $420 \mathrm{bp}$, LSU: $500 \mathrm{bp}$, tub2: $286 \mathrm{bp}$, rpb2: $603 \mathrm{bp}$ ) for three and four regions, respectively. Of those characters 1233 bp (ITS: 324 bp, LSU: 450 bp, tub2: 176 bp, rpb2: 283 bp) were constant and 576 bp (ITS: 96 bp, LSU: 50 bp, tub2: 110 bp, rpb2: 320 bp) were variable. The best-fitting ML nucleotide substitution model for phylogenetic analysis of three-locus and four-locus combined datasets were selected Tamura-Nei $(\mathrm{TN} 93+\mathrm{G}+\mathrm{I})$ and General Time Reversible $(\mathrm{GTR}+\mathrm{G}+\mathrm{I})$ models, respectively. The phylogenetic trees of the maximum likelihood analysis based on both combined datasets are shown in Figs 3 and 4. The topology of phylogenetic trees showed very little differences, and both trees presented generally consistent relationships among the strongly supported clades (Figs 3, 4). The trees topology of both three- and four-locus phylogenetic analysis provided the evidence that the isolates under study were associated with the species Didymella microchlamydospora. In both trees, our isolates and a reference strain from GenBank, D. microchlamydospora CBS 105.95, generated supportive monophyletic clades with strong BS $99 \%$ and 100\% support. In both trees, the reference strain of Neoascochyta exitialis CBS 118.40 among the representative members of the family Didymellaceae positioned as a basal taxon. In addition, the trees obtained through maximum parsimony analysis supported the tree obtained from ML analysis (not shown). 

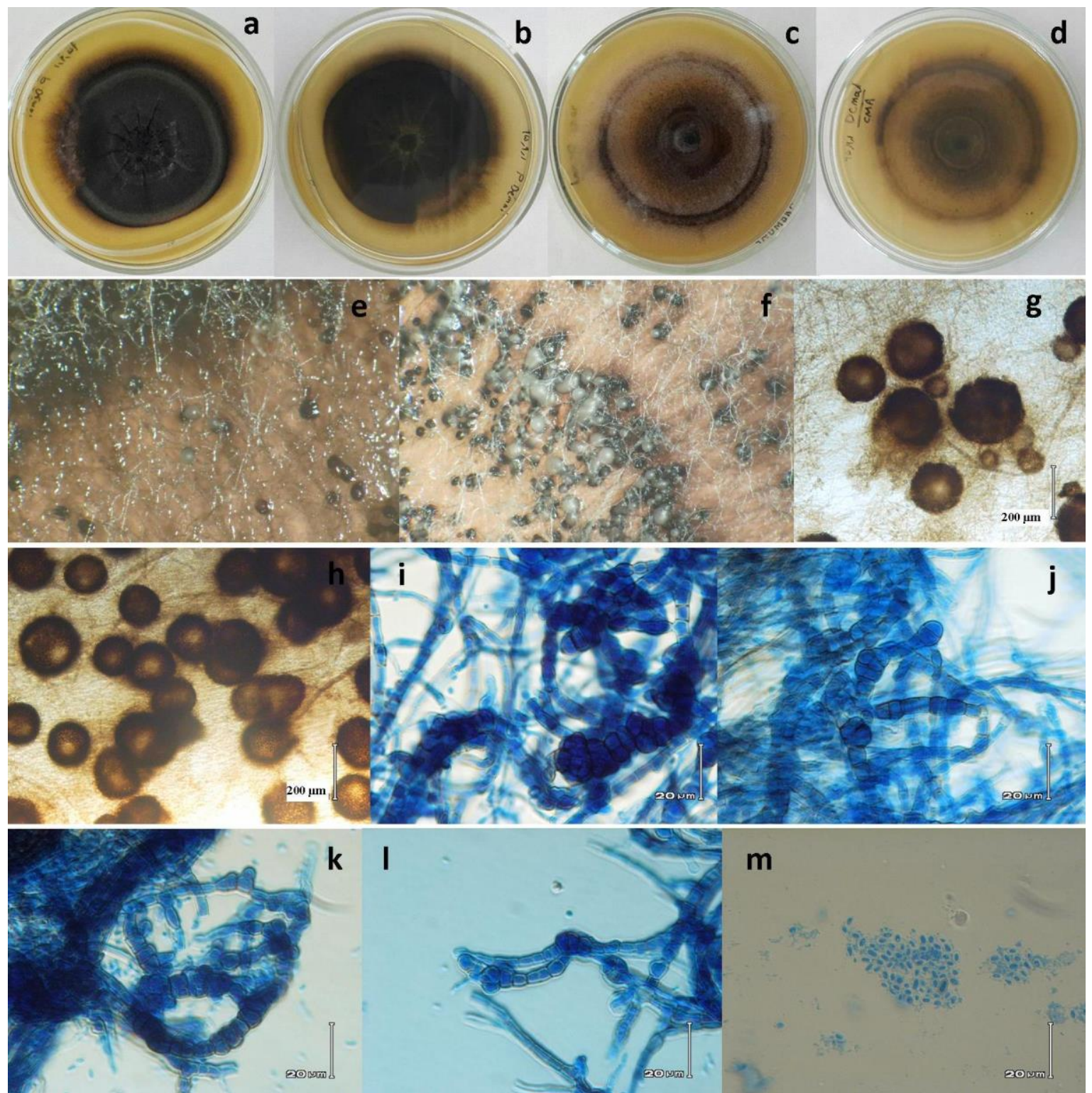

m

Figure 2 - Didymella microchlamydospora isolate SCUA 14_Dez_Mor. a, b Colony on PDA (front and reverse). c, d Colony on CMA (front and reverse). e, f, g, h Pycnidia formed on PDA and CMA. i, j, k, 1 Chlamydospores. m Conidia.

\section{Ecology and distribution}

In the last decade, some of the decline symptoms including; yellowing, wilting, defoliation, dieback and canker were observed on various tree species in whole area of investigation. This disease affected about 5\% of the various ornamental and fruit trees such as Citrus spp., Eucalyptus spp., Morus spp., Conocarpus erectus, Ziziphus nummularia, Nerium oleander, Juglans regia, Prosopis spicigera, Cupressus semperviren, Punica grenatum, Prosopis stephaniana, Olea europaea, Callistemon viminalis, Bauhinina purpurea, Albizia lebbeck and Cordia mixa. The first observed signs in affected trees were dieback, and in which the dead of infected tissues resulted in the girdling of shoots and branches. Following, the causal fungus developed internally and destroyed the growth rings, which is the characteristic of other stem canker causing agents. Death of branches throughout the crown led to gradual tree decline or the tree was dying starting from the top of the crown. An attempt was made to identify the potential canker pathogens and other associated agents. In all, 48 samples were surveyed, 49 isolates of potential pathogenic fungi were detected (unduplicated data), and seven isolates were identified as Didymella microchlamydospora. The isolates of Didymella microchlamydospora SCUA 11-And_Ole and SCUA 12-Ahv_Ole were 


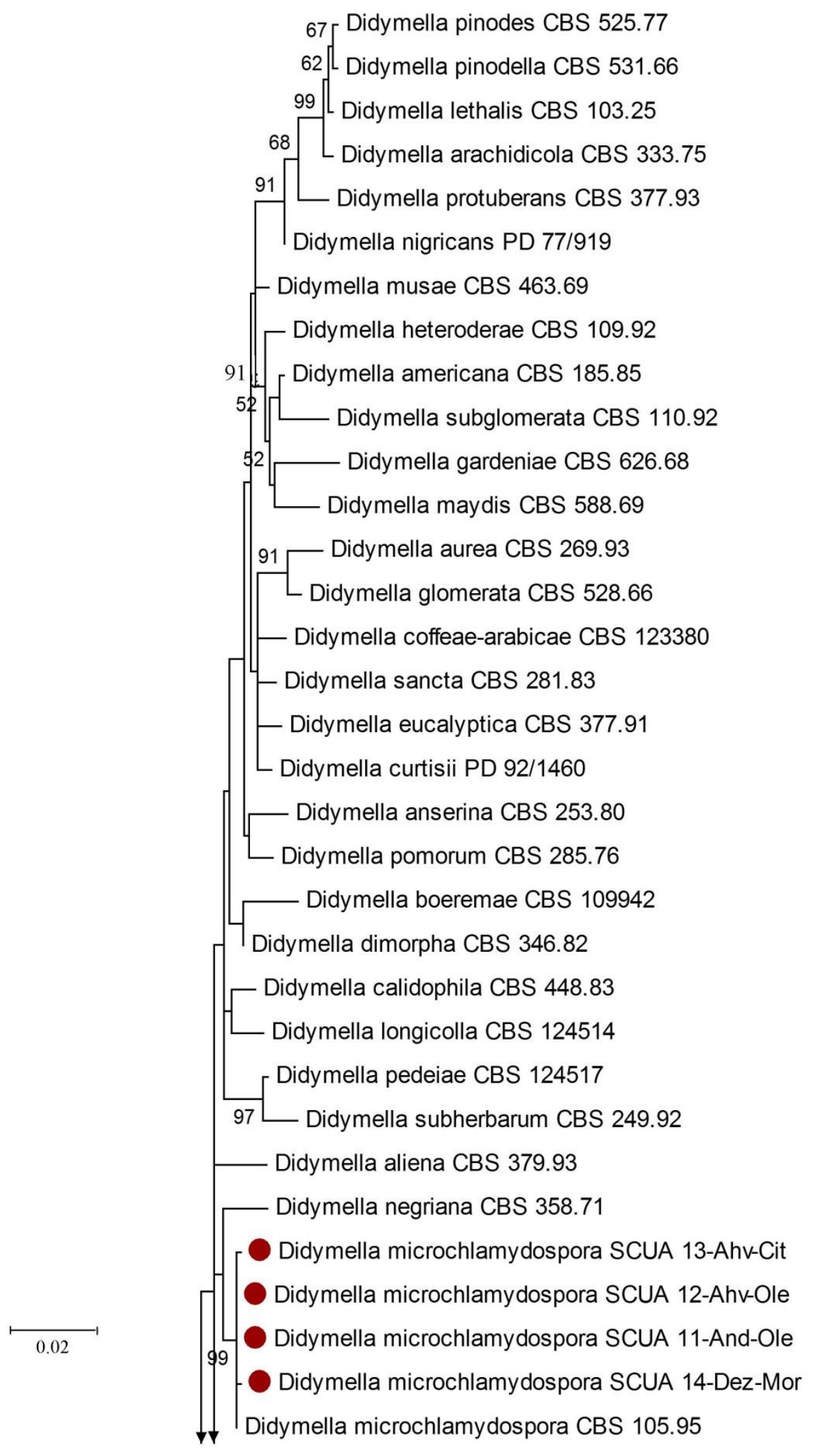

Figure 3 - Phylogenetic tree constructed from a maximum likelihood analysis based on a concatenated alignment of ITS, LSU and tub2 sequences of four Didymella microchlamydospora isolates under study and 16 type strains representing a type species of each described genus of Didymellaceae and 42 described species of genus Didymella downloaded from GenBank. Bootstrap values greater than $50 \%$ (expressed as percentages of 1000 replications) are shown at the nodes. The tree was rooted with Pleospora betae CBS 523.66. 




Figure 3 (continued) 


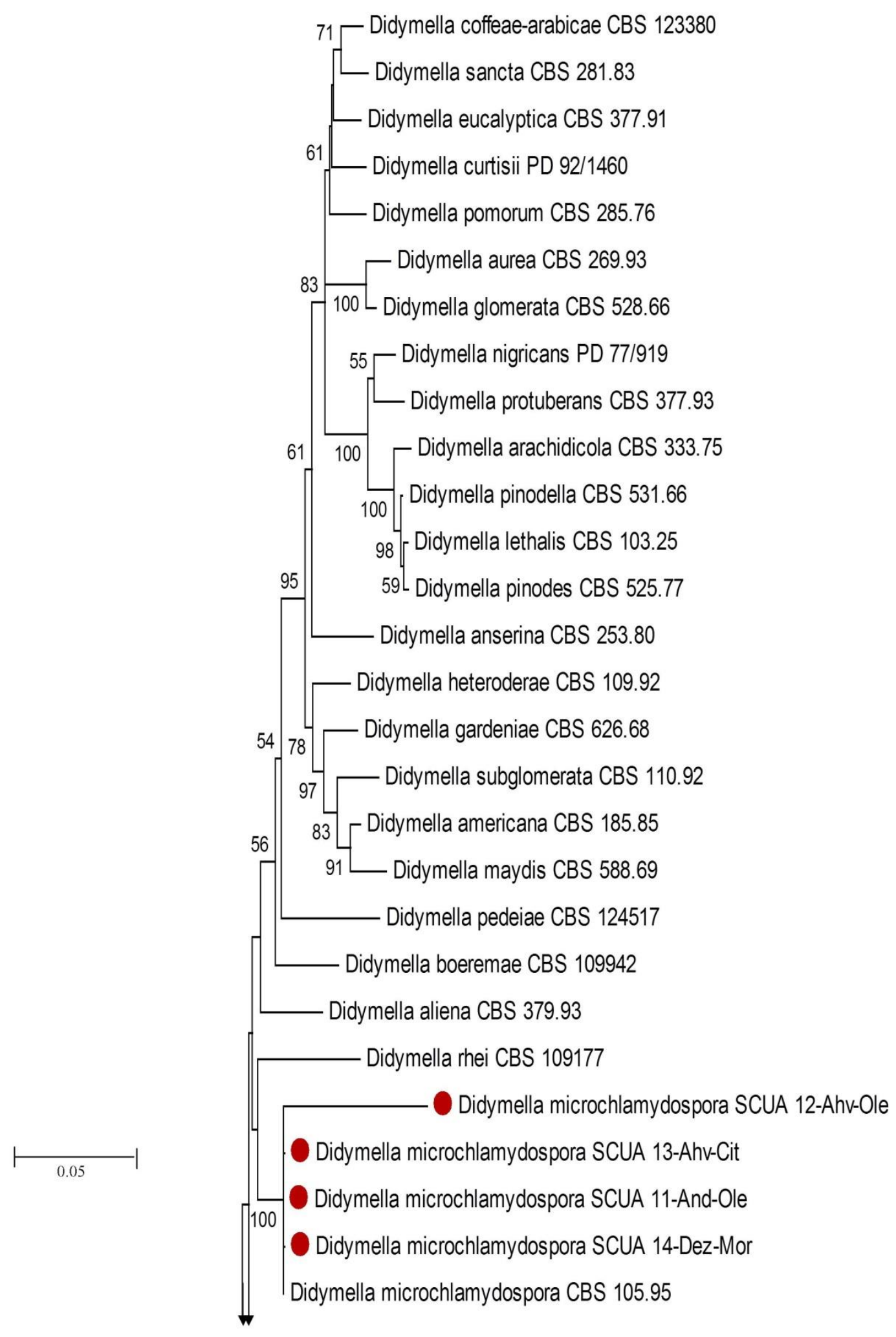

Figure 4 - Phylogenetic tree constructed from a maximum likelihood analysis based on a concatenated alignment of ITS, LSU, tub2 and rpb2 sequences of four Didymella microchlamydospora isolates under study and 16 type strains representing a type species of each described genus of Didymellaceae and 35 described species of genus Didymella downloaded from GenBank. Bootstrap values greater than 50\% (expressed as percentages of 1000 replications) are shown at the nodes. The tree was rooted with Pleospora betae CBS 523.66. 


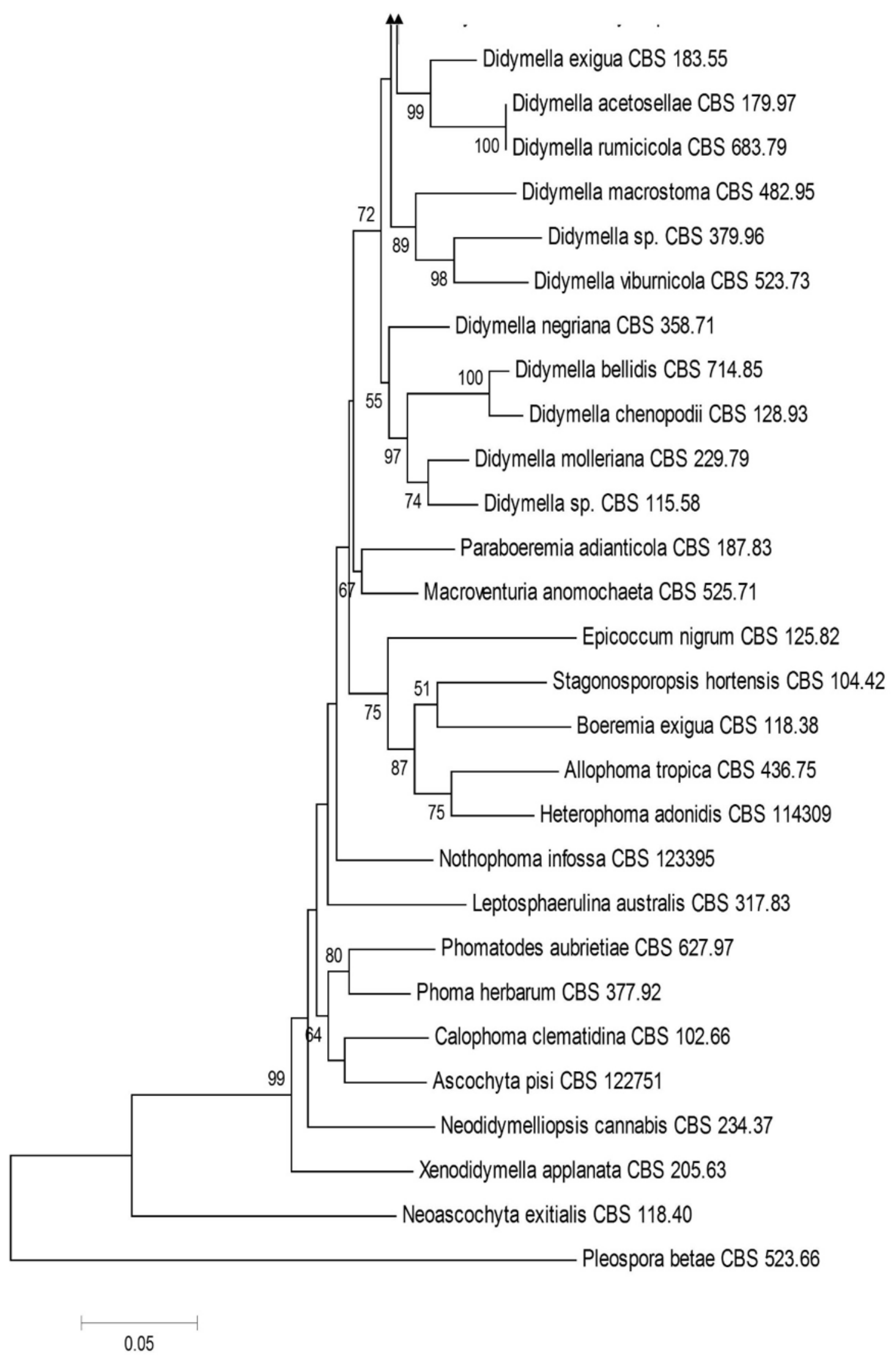

Figure 4 (continued) 
firstly isolated from dead branches of olive (Olea europaea, Oleaceae) in Andimeshk and Ahvaz, and then subsequently, D. microchlamydospora SCUA 13-Ahv_Cit from Bitter orange (Citrus aurantium, Rutaceae) in Ahvaz, D. microchlamydospora SCUA 14-Dez_Mor from blackberry (Morus nigra, Moraceae) in Dezful, D. microchlamydospora SCUA 15- Ahv_Ner from oleander (Nerium oleander, Apocynaceae) in Ahvaz and D. microchlamydospora SCUA 16Ahv_Cal from weeping bottlebrush (Callistemon viminalis, Myrtaceae) in Ahvaz.

\section{Pathogenicity tests}

Both isolates of Didymella microchlamydospora SCUA 11_And_Ole and D. microchlamydospora SCUA 14_Dez_Mor were able to grow and sporulate in the bark surrounding the inoculation point on stem fragments of Olea europaea and Morus nigra, respectively. The isolate of D. microchlamydospora SCUA 14_Dez_Mor developed the external longitudinal lesion on the inoculation point three weeks after inoculation, which was associated with wood necrosis and discoloration in xylem (Fig. 1), while the isolate of D. microchlamydospora SCUA 11_And_Ole did not. In both test plants, the callus was not formed around the inoculation wound. This pathogenic fungus was re-isolated from necrosis-like areas formed on stem fragments of $M$. nigra, and the identity as D. microchlamydospora species was confirmed by morphological characterization.

\section{Discussion}

In our study, seven Didymella microchlamydospora isolates were recovered from 48 plant species. This is the first report of D. microchlamydospora in Iran. Phoma microchlamydospora Aveskamp \& Verkley, was described by Aveskamp et al. (2009), and then, recombined into Didymella microchlamydospora by Chen et al. (2015). Here, further morphological and molecular characterization, pathogenicity on Morus nigra, and a phylogenetic analysis between the isolates under study and other species within the Didymellaceae was evaluated.

In morphology, our isolates are slightly different from reference strain of $D$. microchlamydospora CBS 105.95. The diameter of macropycnidia was less than to the strain $D$. microchlamydospora CBS 105.95 (100-190 vs. 150-260 $\mu \mathrm{m}$ ) (Aveskamp et al. 2009). In similar to the reference strain (Aveskamp et al. 2009), our isolates produced ostiolate and papillate pycnidia, but rarely on a distinct neck as described for D. microchlamydospora CBS 105.95. The width and length of conidia and unicellular chlamydospores are somewhat different but it cannot be used to distinguish the species from each other. The numerous measurements in this study and previous observations (McPartland 1994, Chen et al. 2015) demonstrated that, in general, the conidial length is much more variable, and the conidial size mostly depends on the location of pycnidia. Furthermore, Conidia in pycnidia produced on culture have been usually observed somewhat larger than those from living host (McPartland 1994).

In the current study, the identification of Didymella microchlamydospora isolates based on morphological characterization and BLAST search algorithm is strongly supported in multi-locus phylogeny based on the combined regions of ITS, LSU, tub2 and rpb2. Four isolates of $D$. microchlamydospora were used in the phylogenetic analyses for constructing two phylograms based on three-locus (ITS-LSU-tub2) and four-locus (ITS-LSU-tub2-rpb2) based combined datasets. In both three- and four- locus based phylogenetic trees, sequence dataset worked well to distinguish closely related species in Didymella and our isolates clustered with reference strain $D$. microchlamydospora CBS 105.95, distinct from the other Didymella species (Figs 3, 4). Analysis of congruence between the ITS, LSU, tub2 and rpb2 loci used in the phylogenetic analysis showed that the LSU region had the lowest correlation scores with $10 \%$ sequence diversity and rpb2 region had the highest correlation scores with 53\% sequence diversity. This was most probably due to the low resolution provided by the LSU, which was expected due to the nature of its evolution within species. The LSU locus shared 90\% sequence identify between the species of Didymellaceae, indicating their close phylogenetic relationship. However, the LSU locus of filamentous fungi is often not sufficient to delimit taxa at the species level (Lumbsch et al. 2000, Eberhardt 2010). Due 
to the abundant homoplasy in phenotypic characteristics and difficulties in the morphological identification, it is difficult to distinguish Phoma-like taxa including, the species of Didymella (Chen et al. 2015). Genealogical concordance analysis using several unlinked DNA loci have been already resulted in the dramatic taxonomic changes in Phoma and Phoma-like genera (de Gruyter et al. 2009, 2010, 2012, Aveskamp et al. 2010, Ariyawansa et al. 2015, Chen et al. 2015, Liu et al. 2015, Hyde et al. 2016, Li et al. 2016, Tibpromma et al. 2017) as well as other fungi such as in Alternaria (Woudenberg et al. 2013), Bipolaris (Manamgoda et al. 2011, 2012), Colletotrichum (Cannon et al. 2012, Jayawardena et al. 2016), Fusarium (Short et al. 2013, Laurence et al. 2014), Phyllosticta (Wikee et al. 2011, Hyde et al. 2014), Trichoderma (Druzhinina et al. 2010) and other taxa in Kingdom Myceteae (Ariyawansa et al. 2015, Crous et al. 2015, Liu et al. 2015, Hyde et al. 2016, Li et al. 2016, Tibpromma et al. 2017). Chen et al. (2015) have indicated, that the combined sequence of ITS, LSU, tub2 and rpb2 work well in demarcating Didymella species. The results of these phylogenetic analyses validate the species delimitation of our isolates as $D$. microchlamydospora.

In pathogenicity tests, of the four tested isolates, D. microchlamydospora SCUA 14_Dez_Mor formed the necrosis symptom on stem fragments of Morus nigra (Fig. 1). Dark brown to black discoloration expanded rapidly in a longitudinal direction. Previous studies have shown that Didymella pinodes on Pisum sativum (Tivoli \& Banniza 2007, Barilli et al. 2016) and Didymella tanaceti and Didymella rosea on pyrethrum plant (Pearce et al. 2016) acts as a phytopathogen in the UK and Australia, respectively. Chen et al. (2015) and Pearce et al. (2016) supported the placement of these phytopathogenic species in Didymella sensu stricto. In our study, one isolate of Didymella microchlamydospora infected plant hosts and developed necrosis symptoms. To the best of our knowledge, this is the first phyto-pathogenicity report for Didymella microchlamydospora worldwide.

Observational assessment of areas sampled showed, the disease index and tree mortality positively correlates with environmental stress. Since drought and extremely hot summers became more common in Khuzestan during the last decade, higher than usual incidence of die back diseases may be due to drought stresses and higher annual temperatures that made trees more susceptible to the disease. Observational assessment showed that there was a clear increase in decline symptoms in the zones with low fertility soils, deficiency of water, prolonged exposure to extremely high temperatures, summer sunscald, nutritional imbalances, soil compaction, changes in the soil grade and mechanical injuries. Previous studies showed that environmental stress, such as high temperatures and drought periods could play a role in increasing the virulence and expansion of the Didymellaceae, Botryosphaeriaceae and other decline pathogens (Smith et al. 1996, Kim et al. 2001, Arnold \& Herre 2003, Desprez-Loustau et al. 2007, Slippers \& Wingfield 2007, Botella et al. 2010, Dissanayake et al. 2015, Fan et al. 2016, Anonym 2017, Delgado-Cerrone 2017).

\section{References}

Anonym. 2017 - Thousand cankers disease survey guidelines for 2017. United States Department of Agriculture, Forest Service (FS) and Plant Protection and Quarantine (PPQ), USA.

Ariyawansa HA, Hyde KD, Jayasiri SC et al. 2015 - Fungal diversity notes 111-252: taxonomic and phylogenetic contributions to fungal taxa. Fungal Diversity 75, 27-274.

Arnold AE, Herre EA. 2003 - Canopy cover and leaf age affect colonization by tropical fungal endophytes: ecological pattern and process in Theobroma cacao (Malvaceae). Mycologia 95, 388-398.

Aveskamp MM, Verkley GJ, De Gruyter J, Murace MA et al. 2009 - DNA phylogeny reveals polyphyly of Phoma section Peyronellaea and multiple taxonomic novelties. Mycologia 101, 363-382.

Aveskamp M, De Gruyter J, Woudenberg J, Verkley G, Crous PW. 2010 - Highlights of the Didymellaceae: a polyphasic approach to characterise Phoma and related pleosporalean genera. Studies in Mycology 65, 1-60. 
Barilli E, Cobos MJ, Rubiales D. 2016 - Clarification on Host Range of Didymella pinodes the Causal Agent of Pea Ascochyta Blight. Frontiers in Plant Science 7, 592-608.

Botella L, Santamaría O, Diez J. 2010 - Fungi associated with the decline of Pinus halepensis in Spain. Fungal Diversity 40, 1-11.

Cannon P, Damm U, Johnston P, Weir B. 2012 - Colletotrichum-current status and future directions. Studies in Mycology 73, 181-213.

Chen Q, Jiang J, Zhang G, Cai L, Crous P. 2015 - Resolving the Phoma enigma. Studies in Mycology 82, 137-217.

Corlett M. 1981 - A taxonomic survey of some species of Didymella and Didymella-like species. Canadian Journal of Botany 59, 2016-2042.

Crous PW, Schumache RK, Wingfield MJ, Lombard L et al. 2015 - Fungal Systematics and Evolution: FUSE 1. Sydowia 67, 81-118.

Crouse J, Amorese D. 1987 - Ethanol precipitation: ammonium acetate as an alternative to sodium acetate. Focus 9, 3-5.

De Gruyter J, Aveskamp MM, Woudenberg JH, Verkley GJ et al. 2009 - Molecular phylogeny of Phoma and allied anamorph genera: towards a reclassification of the Phoma complex. Mycological Research 113, 508-519.

De Gruyter J, Woudenberg JH, Aveskamp MM, Verkley GJ et al. 2010 - Systematic reappraisal of species in Phoma section Paraphoma, Pyrenochaeta and Pleurophoma. Mycologia 102, 1066-1081.

De Gruyter J, Woudenberg J, Aveskamp M, Verkley G et al. 2012 - Redisposition of Phoma-like anamorphs in Pleosporales. Studies in Mycology 75, 1-36.

Delgado-Cerrone L, Mondino-Hintz P, Alaniz-Ferro S. 2016 - Botryosphaeriaceae species associated with stem canker, die-back and fruit rot on apple in Uruguay. European Journal of Plant Pathology 146, 637-655.

Desprez-Loustau ML, Robin C, Reynaud G, Déqué M et al. 2007 - Simulating the effects of a climate-change scenario on the geographical range and activity of forest-pathogenic fungi. Canadian Journal of Plant Pathology 29, 101-120.

Dissanayake AJ, Zhang W, li X, Zhou Y et al. 2015 - First report of Neofusicoccum mangiferae associated with grapevine dieback in China. Phytopathologia Mediterranea 54, 414-419.

Druzhinina IS, Kubicek CP, Komoń-Zelazowska M, Mulaw TB, Bissett J. 2010 - The Trichoderma harzianum demon: complex speciation history resulting in coexistence of hypothetical biological species, recent agamospecies and numerous relict lineages. BMC Evolutionary Biology 10, 94-96.

Eberhardt U. 2010 - A constructive step towards selecting a DNA barcode for fungi. New Phytologist 187, 265-8.

Fan XL, Du Z, Hyde KD, Liang YM et al. 2016 - Cryptosporella platyphylla, a new species associated with Betula platyphylla in China. Phytotaxa 253, 285-292.

Hall TA. 1999 - BioEdit: a user-friendly biological sequence alignment editor and analysis program for Windows 95/98/NT. In: Nucleic acids symposium series 41, 95-98.

Holm L. 1975 - Nomenclatural notes on Pyrenomycetes. Taxon 24, 475-488.

Horst RK. 2013 - Field manual of diseases on trees and shrubs. Springer Dordrecht Heidelberg, New York.

Hyde KD, Jones EBG, Liu JK, Ariyawansa H et al. 2013 - Families of Dothideomycetes. Fungal Diversity 63, 1-313.

Hyde KD, Nilsson RH, Alias SA, Ariyawansa HA et al. 2014 - One stop shop: backbones trees for important phytopathogenic genera:I. Fungal Diversity 67, 21-125.

Hyde KD, Hongsanan S, Jeewon R, Bhat DJ et al. 2016 - Fungal Diversity. notes 367- 490: taxonomic and phylogenetic contributions to fungal taxa. Fungal Diversity 80, 1-270.

Jayawardena RS, Hyde KD, Damm U, Cai L et al. 2016 -Notes on currently accepted species of Colletotrichum. Mycosphere 7, 1192-1260. 
Kim KW, Lee IJ, Thoungchaleun V, Kim CS et al. 2009 - Visualization of wound periderm and hyphal profiles in pine stems inoculated with the pitch canker fungus Fusarium circinatum. Microscopy Research and Technique 72, 965-973.

Kornerup A, Wanscher JH. 1967 - Methuen handbook of colour. Methuen handbook of colour. Methuen \& Co. Ltd., London.

Laurence HM, Summerell BA, Burgess LW, Liew ECY. 2014 - Genealogical concordance phylogenetic species recognition in the Fusarium oxysporum species complex. Fungal Biology 118, 374-384.

Lawrence DP, Travadon R, Baumgartner K. 2015 - Diversity of Diaporthe species associated with wood cankers of fruit and nut crops in northern California. Mycologia 107, 926-40.

Li GJ, Hyde HD, Zhao RL, Hongsanan S et al. 2016 - Fungal diversity notes 253-366: taxonomic and phylogenetic contributions to fungal taxa. Fungal Diversity 78, 1-237.

Liu JK, Hyde, KD, Jones EBG, Ariyawansa HA et al. 2015 - Fungal diversity notes 1-110: taxonomic and phylogenetic contributions to fungal species. Fungal Diversity 72, 1-197.

Liu YJ, Whelen S, Hall BD. 1999 - Phylogenetic relationships among Ascomycetes: evidence from an RNA polymerse II subunit. Molecular Biology and Evolution 16, 1799-1808.

Lumbsch H. 2000 - Phylogeny of filamentous Ascomycetes. Naturwissenschaften 87, 335-342.

Manamgoda DS, Cai L, Bahkali AH, Chukeatirote E et al. 2011 - Cochliobolus: an overview and current status of species. Fungal Diversity 51, 3-42.

Manamgoda DS, Cai L, McKenzie EHC, Crous PW et al. 2012 - A phylogenetic and taxonomic reevaluation of the Bipolaris - Cochliobolus - Curvularia complex. Fungal Diversity 56, 131144.

McPartland J. 1994 - Cannabis pathogens X: Phoma, Ascochyta and Didymella species. Mycologia $86,870-878$.

O'Donnell K. 1993 - Fusarium and ITS near relatives. In: Reynolds DR, Taylor JW (ed) The Fungal Holomorph: Mitotic, Meiotic and Pleomorphic Speciation in Fungal Systematics, Wallingford, UK: CAB International, pp 225-233.

Pearce T, Scott J, Crous P, Pethybridge S, Hay F. 2016 - Tan spot of Pyrethrum is caused by a Didymella species complex. Plant Pathology 65, 1170-1184.

Phillips A, Alves A, Abdollahzadeh J, Slippers B et al. 2013 - The Botryosphaeriaceae: genera and species known from culture. Studies in Mycology 76, 51-167.

Raeder U, Broda P. 1985 - Rapid preparation of DNA from filamentous fungi. Letters in Applied Microbiology 1, 17-20.

Rayner MC. 1922 - Nitrogen fixation in Ericaceae. Botanical gazette 73, 226-235.

Riddle O, Briggs FN. 1950 - Inheritance of resistance to scald in barley. Hilgardia 20, 19-27.

Saccardo P. 1880 - Conspectus generum fungorum Italiae inferiorum, nempe ad Sphaerosideas, Melanconieas et Hyphomyceteas pertinentium, systemate sporologico dispositum. Michelia 2, 33.

Short DP, O'Donnell K, Thrane U, Nielsen KF et al. 2013 - Phylogenetic relationships among members of the Fusarium solani species complex in human infections and the descriptions of $F$. keratoplasticum sp. nov. and F. petroliphilum stat. nov. Fungal Genetics and Biology 53, 59-70.

Shurtleff MC. 1997 - Deter canker and dieback diseases. Grounds Maintenance 32, 49-56.

Sinclair WA, Lyon HH, Johnson WT. 1987 - Diseases of trees and shrubs. Cornell University Press, Ithaca, NY.

Slippers B, Wingfield MJ. 2007 - Botryosphaeriaceae as endophytes and latent pathogens of woody plants: diversity, ecology and impact. Fungal Biology Reviews 21(2), 90-106.

Smith H, Wingfield M, Petrini O. 1996 - Botryosphaeria dothidea endophytic in Eucalyptus grandis and Eucalyptus nitens in South Africa. Forest ecology and management 89, 189-195.

Sung G-H, Sung J-M, Hywel-Jones NL, Spatafora JW. 2007 - A multi-gene phylogeny of Clavicipitaceae (Ascomycota, Fungi): Identification of localized incongruence using a combinational bootstrap approach. Molecular Phylogenetics and Evolution 44, 1204-1223. 
Tamura K, Stecher G, Peterson D, Filipski A, Kumar S. 2013 - MEGA6: molecular evolutionary genetics analysis version 6.0. Molecular biology and evolution 30, 2725-2729.

Tibpromma S, Hyde KD, Jeewon R et al. 2017 - Fungal diversity notes 491-602: taxonomic and phylogenetic contributions to fungal taxa. Fungal Diversity 83, 1-261.

Tivoli B, Banniza S. 2007 - Comparison of the epidemiology of Ascochyta blights on grain legumes. Europian Journal of Plant Pathology 119, 59-76.

White TJ, Bruns T, Lee S, Taylor J. 1990 - Amplification and direct sequencing of fungal ribosomal RNA genes for phylogenetics. PCR protocols: a guide to methods and applications $18,315-322$

Wijayawardene NN, Crous PD, Kirk PM, Hawksworth DL et al. 2014 - Naming and outline of Dothideomycetes-2014 including proposals for the protection or suppression of generic names. Fungal Diversity 69, 1-55.

Wikee S, Udayanga D, Crous PW, Chukeatirote E et al. 2011 - Phyllosticta - an overview of current status of species recognition. Fungal Diversity 51, 43-61.

Woudenberg J, Aveskamp M, De Gruyter J, Spiers A, Crous P. 2009 - Multiple Didymella teleomorphs are linked to the Phoma clematidina morphotype. Persoonia-Molecular Phylogeny and Evolution of Fungi 22, 56-62.

Woudenberg JHC, Groenewald JZ, Binder M, Crous PW. 2013 - Alternaria redefined. Studies in Mycology 75, 171-212. 